\title{
La arbitrabilidad de las patentes de invención
}

\author{
Andrés W. Chugá Porras* \\ Recibido/Received: 16/09/2019 \\ Aceptado/Accepted: 01/10/2019
}

\begin{abstract}
SUMARIO: 1. Las patentes de invención y sus características para definir su arbitrabilidad. 1.1 Respecto del titular. 1.2 Respecto de la sociedad. 2. Materia transigible o arbitrabilidad de las patentes de invención. 2.1 La arbitrabilidad, transigibilidad o disponibilidad. 2.2 La arbitrabilidad objetiva o ratione materiae. 2.3 La arbitrabilidad subjetiva o ratione personae. 2.4 La arbitrabilidad de las patentes de invención respecto de las partes. 2.5 La arbitrabilidad de las patentes de invención respecto de la sociedad y orden público. 3. Comentario final.
\end{abstract}

Resumen: Una patente de invención debe cumplir determinados requisitos para obtener la protección Estatal y brindar a su titular el derecho de explotación exclusiva. Sin embargo, por tratarse de un derecho que otorga 20 años de protección al titular y retira del alcance de los demás su explotación implica que habrá, en algún momento, afectación al orden público. Es precisamente que su arbitrabilidad se ve afectada y complicada por ser un derecho que se supedita a una aprobación estatal y además que afecta a la sociedad en general.

Palabras Clave: arbitrabilidad, disponibilidad, patentes de invención, orden público, ius prohibendi.

\footnotetext{
* Socio principal de la firma Chugá Porras Abogados, Abogado por la Pontificia Universidad Católica del Ecuador, Máster en Propiedad Intelectual por la Universidad Austral de Argentina. Correo electrónico: a.chugaporras@cplaw.com.ec

A. W. Chugá Porras, "La arbitrabilidad de las patentes de inversión", Revista Ecuatoriana de Arbitraje, No. 10, 2019, pp. 115-136.
} 


\section{Arbitrability of invention patents}

Aвstract: A patent of invention must meet the requirements to obtain effective protection from the State and give its owner the right to exclusive exploitation. However, because it is a right that grants 20 years of protection to the holder and withdraws from the reach of others its implied exploitation that will, at some point, affect public order. Its arbitrability is limited by the fact that the right was granted by the State and also affects society in general.

KeYwords: arbitrability, availability, patent of invention, public policy, ius prohibendi.

\section{LAS PATENTES DE INVENCIÓN Y SUS CARACTERÍSTICAS PARA DEFINIR SU ARBITRABILIDAD}

Los conceptos y estudios que giran en torno a las patentes de invención son realmente extensos y considero que en vano haría al exponerlos a profundidad en este artículo, puesto que, lo que más interesa es la disponibilidad de los derechos que giran en torno a una patente de invención a fin de que sean susceptibles de ser discutidos en un arbitraje, nacional o internacional, y por ende obtener una decisión vinculante o final.

Se tiene una idea clara de que una de las justificaciones de la patente de invención es el rol que representa en el sistema económico de los países como incentivo al desarrollo de nuevas tecnologías, precisamente al conceder un monopolio sobre las invenciones ${ }^{1}$.

En palabras del profesor Manuel BotAnA AgrA, la protección a una invención radica en

1. Véase, G. Cabanellas De Las Cuevas, Derecho de las patentes de invención, Tomo I, 2da Ed., Editorial Heliasta, 2004, p. 51. 
las posibilidades que en principio encierra la propia invención de crear posiciones de explotación exclusiva, pueden erigirse en estímulo suficiente para que, sin recurrir, a otros instrumentos estimulantes, los humanos dediquen esfuerzos y recursos de toda índole a la permanente generación de reglas inventadas (lo que, por lo demás, supone un reforzamiento de la innata inclinación del ser humano a desentrañar la esencia de cuanto lo rodea y a llegar al conocimiento de lo que se le manifiesta como "desconocido" $)^{2}$.

Conforme lo establecido en la doctrina y legislación, nacional e internacional ${ }^{3}$, los tres requisitos para que un invento sea patentable y pueda obtener protección a través de la concesión de una patente son: (i) novedad; (ii) nivel inventivo; (iii) y aplicación industrial ${ }^{4}$.

Ahora bien, teniendo en consideración lo que se requiere para obtener una patente de invención es preciso exponer los efectos que la obtención de un título de patente otorga, tanto para el titular de la patente como para la sociedad en general -incluyendo el Estado-.

\subsection{Respecto del titular}

En caso de que una solicitud de patente de invención cumpla los requisitos para su otorgamiento el titular de la patentegozará delos derechos concedidos por la entidad estatal, como consecuencia del nivel de tecnicidad en el desarrollo de un invento (como por ejemplo el nivel inventivo) lo cual no se aplica para otras figuras en la Propiedad Intelectual, por ende, el aporte tecnológico es mayor y la protección más extensa; como consecuencia de esto "el interés público indica que lo

2. C. Fernández-Nóvoa, J. M. Otero Lastres \& M. Botana Agra, Manual de la Propiedad Industrial, 2da Ed., Marcial Pons Ediciones Jurídicas y Sociales, S.A., 2013, p. 103.

3. Salvo determinados casos como la legislación de los Estados Unidos de América donde se requiere que una patente de invención sea: elegible, nueva, útil y no obvia.

4. Esto ha sido aceptado por los países suscriptores de la Organización Mundial del Comercio, a través del Acuerdo sobre los Aspectos de los Derechos de Propiedad Intelectual relacionados con el Comercio - ADPIC, en su artículo 27. 
más conveniente es que la tecnología se divulgue se tutela en general en mayor medida al titular de la patente de invención, que entrega más a la sociedad" ${ }^{\prime \prime}$.

La doctrina cataloga a los derechos que posee el titular de una patente de invención como positivos y negativos ${ }^{6}$, es decir, el titular bien podrá explotar los derechos que recaen sobre su invento, autorizar el uso del mismo, o, por otro lado, bien podrá prohibir dicho uso a terceros; ; a pesar de esto se debe tener en mente que un derecho intelectual es erga omnes ${ }^{8}$ (incluyendo el de inventar y desarrollar), no obstante, siguiendo la línea de pensamiento, en uso de los derechos sobre una patente de invención se excluye de la sociedad la utilización libre de esa tecnología, también conocido como el ius prohibendi.

Como lo expone Cortés Rosso, el derecho de patente "implica, por un lado, una limitación al derecho a desarrollar cualquier actividad económica lícita y, por otro lado, una limitación a la propiedad que esas personas o asociaciones tengan sobre ciertos bienes materiales [...] si el derecho de patente implica que a todas las personas y asociaciones no autorizadas les está vedada la explotación de determinada tecnología patentada se desprende que su derecho constitucional a desarrollar cualquier actividad económica que no sea contraria a la moral, al orden público o a la seguridad nacional, respetando las normas legales que la regulen [...] se encuentra limitado".

Ahora bien, esta categoría ha sido ampliamente debatida por la doctrina puesto que, como lo indica el profesor Cabanellas sobre los derechos positivos de una patente, "[e] ste no otorga un derecho a la explotación de la invención, a

5. M. Cortés Rosso, Patentes de Invención: Aspectos Jurídicos, 1era Ed., LegalPublishing Chile, 2012, p. 53.

6. Entre otras categorías.

7. Véase, M. CoRtés Rosso, N. 5, p. 66.

8. Véase, G. Cabanellas De las Cuevas, N. 1, p. 563. 
favor del titular de la patente, pues ese derecho no depende de la patente ni el hecho de que exista la patente asegura que tal derecho efectivamente está presente", sin embargo, se podría tener en consideración que el derecho de la patente representa un todo y está ligada la parte positiva con la negativa.

Sobre lo mencionado, puedo acotar el siguiente silogismo y un análisis personal:

(i) La idea nace en el fuero interno de la persona y eso la convierte en un "posible" derecho de Propiedad Intelectual, salvo los derechos de autor, puesto que la normativa positiva ha determinado requisitos para cada figura.

(ii) Posteriormente, el inventor expresa su idea en algo tangible, sin embargo, hasta este momento, no tiene tutela jurídica o protección del Estado y por ende no tiene derecho de patente. Como consecuencia de la idea que tuvo el inventor, posee una "supuesta" libertad de desarrollar su idea en algo tangible y explotarlo como guste, no obstante aún no posee un derecho de Propiedad Intelectual, por lo que mas bien está incurriendo en dos posibles escenarios: a) una especie de limbo por utilizar algo que aún no es reconocido como un derecho; $\mathrm{y}, \mathrm{b})$ está infringiendo la patente de otra persona por lo que tampoco tiene un derecho de explotación porque no tiene certeza si puede explotarla o no.

(iii)Como consecuencia de esto y tras este breve silogismo, es muy probable que una patente de invención sí otorgue derechos positivos y negativos. Desarrollar o crear algo no implica que se ha desarrollado o creado algo que sea susceptible de patentabilidad ni mucho menos susceptible de explotación, tal vez la patente no es un "requisito" para la explotación pero si es un reconocimiento de que no se está infringiendo otra patente. Un invento no es una 
patente pero un invento protegido por una patente es una garantía de que posee novedad, nivel inventivo y aplicación industrial, puesto que ya pasó por todas las instancias administrativas como el examen de patentabilidad y oposiciones de terceros. No se puede hablar de un derecho negativo en una patente de invención como el ius prohibendi si no se tiene un derecho positivo como el reconocimiento de un invento como una patente porque si bien no es un requisito la patente para la explotación, tampoco tendrá la persona el derecho de prohibir el uso de su creación porque no tiene una patente.

Sobre este punto Miguel Botana Agra manifiesta "[c]omo consecuencia de su propio concepto, la invención genera por sí misma una especie de sistema de autodefensa [...] al consistir en una regla para el obrar humano técnico hasta entonces 'no conocida', la invención coloca a su creador en una situación fáctica de monopolio a la hora de su explotación económica"9 lo cual complementa con la afirmación que

la declaración de [...] la patente confiere a su titular un derecho de utilización exclusiva de la invención patentada (vertiente positiva, el ius utendi). Esto no obstante, existen en la LP manifestaciones suficientes (por ejemplo, la posibilidad de expropiación de la patente o la obligación de explotar la invención patentada) que llevan a entender que el derecho de patente no agota su contenido en el ius prohibendi, sino que comprende también facultades y poderes que son expresión de la vertiente positiva o del ius utendi) ${ }^{10}$.

La razón principal del análisis precedentes es porque más adelante nos adentraremos en determinar el "grado" de arbitrabilidad de los derechos que giran entorno a una patente de invención, los cuales, como lo vemos, podrían ser catalogados como aquellos respecto del titular e inclusive del inventor per se -obviamente no siempre será el mismo- como

9. C. Fernández-Nóvoa, J. M. Otero Lastres, M. Botana Agra, N. 2, p. 103.

10. Ídem, p. 167. 
por ejemplo el contratos de licencias, en oposiciones, ventas o cesiones de derechos, herencias, contratación civil para el desarrollo de la patente de invención, y en sí cualquier negocio jurídico o ejercicio que pueda tenerlo dicho titular o su inventor.

\subsection{Respecto de la sociedad}

Ahora bien, por otro lado, tenemos la perspectiva o la consecuencia de la concesión de una patente de invención frente a la sociedad en general.

Afin decomprender la mencionada dimensión esnecesario, en primer lugar, referirnos a los bienes inmateriales para lo cual utilizaré el concepto del profesor José Antonio Gómez SEGADE quien se refiere a estos bienes como "[...] creaciones de la mente humana que mediante los medios adecuados, se hacen perceptibles y utilizables en las relaciones sociales y por su especial importancia económica son objeto de una tutela jurídica especial"11.

En este sentido, haciendo referencia a un decir de la Sierra ecuatoriana "empecemos en el principio y terminemos en el final" que es precisamente lo que haremos. Los derechos que giran en torno a una patente de invención respecto de la sociedad nacen, simplemente -como lo sostiene BotANA AGRA-, de un mosaico el cual está integrado, desde un principio, por el "pacto social" entre el inventor y la sociedad [representada por el poder público] y "[p]or virtud de este pacto el inventor desvela y describe [hace patente] el contenido de la invención por él diseñada $\mathrm{y}$, a cambio, el poder público le concede por un tiempo una posición de exclusiva para la explotación económica de la invención en el mercado"12.

11. J. A. Gómez Segade, "Tecnología y Derecho: Estudios jurídicos del profesor Dr. H. C. José Antonio Gómez Segade recopilados con ocasión de la conmemoración del XXV años de cátedra", Marcial Pons, 2001, en M. CoRTés Rosso, N. 5, p. 66.

12. C. Fernández-Nóvoa, J. M. Otero Lastres, M. Botana Agra,, N. 2, pp. 103-104. 
En este sentido, al obtener esta concesión o aprobación social para el uso exclusivo de una tecnología determinada, por un tiempo y espacio, el inventor o el titular de la patente acepta que una vez fenecido el tiempo por el cual se otorga esta exclusividad, el derecho se extinguirá y pasará al dominio público, lo cual implica que cualquier persona podrá utilizar su tecnología.

No obstante lo mencionado, sin entrar en profundidad del tema, se debe tener presente que el agotamiento del derecho de patente y también su extinción, pueden ser por otras causales que las mencionadas.

El agotamiento del derecho, en forma general, versa sobre dos aspectos: (i) el primero es el límite que tendrá el titular de la patente de invención en ejercer su ius prohibendi; y, (ii) el segundo sobre el conocido agotamiento del derecho internacionalmente, sin embargo, considero que para este estudio será necesario tener en consideración que el agotamiento del derecho guarda cercana relación con la disponibilidad de dicho derecho a fin de someterlo a un arbitraje. Esto es porque si mi derecho se agotó entonces no podría disponer de él o, al contrario, si puedo disponer de mi derecho entonces no se ha agotado.

Respecto de las causales de la extinción del derecho, nuevamente debemos tener en cuenta el decir de la Sierra ecuatoriana, puesto que si el Estado me otorga este derecho entonces no es un derecho que siempre estuvo y, por ende, será susceptible de extinguirse por determinadas razones. Si el invento se supedita a cumplir ciertos requisitos entonces la falta de uno de esos requisitos, así sea demostrado posteriormente a su concesión, causa la extinción de ese derecho; al igual que si se lo otorga por un tiempo, al cumplir ese tiempo, se extingue; asimismo, cuando se dejan de cumplir formalidades como el pago de anualidades; en la misma línea, se extingue el derecho sobre la patente cuando la persona renuncia al derecho de 
patente; o, cuando la patente es concedida sobre la invención y no se la explota en un período determinado.

Todo lo enunciado tiene relación con el orden público y la sociedad porque mientras una patente de invención se encuentre vigente es excluida del dominio público y, asimismo, afecta a la sociedad tanto y cuanto una patente de invención no tiene el requisito de "no afectar al orden público" para su validez, sin embargo, en función de su "objeto" podría hacerlo. Esto lo expone el profesor Cabanellas De Las Cuevas con absoluta precisión cuando sostiene "[i]nclusive, el inventor titular de una patente podrá verse totalmente impedido de explotar la invención, en virtud de disposiciones sanitarias o de otra índole, sin que ello afecte la validez de la patente ni su existencia jurídica"13. No obstante, a fin de determinar la arbitrabilidad de los derechos que giran entorno a una patente de invención se deberá tener en cuenta que en un proceso arbitral se litigarán derechos que son transigibles o que son disponibles, por ende, un proceso arbitral también podría afectar el orden público como lo estudiaremos más adelante.

\section{Materia tRANSigible O ARbitrabilidAd de LAS PATENTES DE INVENCIÓN}

Alo largo de este trabajo he llevado la línea de pensamiento hasta llegar a este punto. El arbitraje existe porque los derechos que se "discuten" son susceptibles de disposición o de transigibilidad y precisamente entender la dimensión o el "alcance" que tiene el titular de un derecho de patente para someterlo a este método alternativo de resolución de conflictos, sin que afecte al orden público pero que siga siendo funcional por las características inherentes del arbitraje, es lo que expondré a continuación.

13. G. Cabanellas De Las Cuevas, N. 1. 


\subsection{La arbitrabilidad, transigibilidad o disponibilidad}

Indistintamente de la palabra que se utilice, hasta el presente momento debemos tener claro que no todos los conflictos son susceptibles de resolverlos en un arbitraje pero sus características son las que lo vuelven oportuno para buscarlo e intentar utilizarlo. Como lo ha mencionado GonzÁlez De Cossio, "[p]ara que un acuerdo arbitral sea válido, debe ser lícito. Es decir, es necesario que la materia sea arbitrable. Susceptible de ser ventilada en arbitraje. Ello surge en dos momentos: en la ejecución del acuerdo arbitral; y en la ejecución del laudo arbitral"14.

Para Gonzalo Quiroga la arbitrabilidad "abarcaría una triple dimensión: como condición impuesta por el derecho de fondo, como condición de validez del convenio arbitral, y como presupuesto que posibilita la no anulación y el reconocimiento y la ejecución de la sentencia arbitral"15.

La Convención de Nueva York menciona en su artículo II, numeral 1, que:

Cada uno de los Estados Contratantes reconocerá el acuerdo por escrito conforme al cual las partes se obliguen a someter a arbitraje todas las diferencias o ciertas diferencias que hayan surgido o puedan surgir entre ellas respecto a una determinada relación jurídica, contractual o no contractual, concerniente a un asunto que pueda ser resuelto por arbitraje"16.

Al mencionar que un asunto pueda ser resuelto por arbitraje, deja en descubierto, como lo hemos mencionado, que existen materias que no podrán ser arbitrables, no obstante, esto dependerá de cada país y su legislación.

14. F. González De Cosío, Arbitraje, p. 195.

15. G. Quiroga, Orden Público y Arbitraje Internacional en el Marco de la Globalización Comercial (Arbitrabilidad y Derecho Aplicado al fondo de la Controversia Internacional), Dykinson, 2003, p. 100.

16. Convención sobre el Reconocimiento y la Ejecución de las Sentencias Arbitrales Extranjeras (1958), Art. II. 
Asimismo, la Ley Modelo de la CNUDMI contempla en su artículo 34,-cuando habla de la petición de nulidad como único recurso al laudo arbitral- que: “El laudo arbitral sólo podrá ser anulado por el tribunal indicado en el artículo 6 cuando: b) el tribunal compruebe: i) que, según la ley de este Estado, el objeto de la controversia no es susceptible de arbitraje"17.

De manera similar, ciertos conflictos relativos a marcas en España pueden ser sometidos a un arbitraje, a pesar de que, a mi parecer, tocan áreas de la Propiedad Intelectual que consideraba eran competencia única del Estado.

El profesor Carlos Fernández-NóvoA explica que “[e]l art. 28 de la Ley de 2001 tiene el mérito de implantar el mecanismo del arbitraje en el contexto del procedimiento de concesión del registro de la marca"18. Es en este sentido que el profesor los divide en tres momentos de estudio: (i) respecto de las cuestiones que cabe someter a arbitraje; (ii) respecto del convenio arbitral; $y$, (iii) el laudo arbitral y sus efectos.

La primera, explica que delimita las cuestiones que son susceptibles de someterse a arbitraje de una forma negativa y de una forma positiva. Indica que por la vía negativa "se excluyen del arbitraje las cuestiones relativas a la concurrencia o no de los requisitos formales del procedimiento, así como la existencia de prohibiciones absolutas de registro"19. Por otro lado, por la vía positiva se puede decir que el arbitraje operaría en:

1. [...] las cuestiones tocantes a la existencia de un riesgo de confusión entre la marca solicitada y una marca anterior esgrimida mediante una oposición [...]. 2. [...] las cuestiones concernientes al conflicto entre la marca solicitada y una marca anterior renombrada o notoriamente conocida. [...] las cuestiones atinentes al conflicto entre la marca solicitada y

17. Ley Modelo de la CNUDMI sobre Arbitraje Comercial Internacional (1985), Art. 34(2)(b).

18. C. Fernández-Nóvoa, J. M. Otero Lastres, M. Botana Agra, N. 2, p. 533.

19. Ibídem. 
los derechos anteriores enunciados en el art. 9 de la Ley de $2001^{\prime \prime 20}$.

Justamente se inició el estudio exponiendo las justificaciones de un arbitraje, lo cual incluyó hablar sobre su naturaleza, y el ejemplo español demuestra la aplicación de la teoría híbrida porque dicha nación decidió, a través de una ley, sobre la arbitrabilidad de las oposiciones de una marca lo cual para una gran mayoría de países resulta sorprendente puesto que se lo maneja de forma administrativa; esto, sin dejar de tener en consideración que las oposiciones marcarias en Argentina se las lleva de forma judicial -lo cual también se vuelve interesante para nuestro estudio-. Al final del litigio arbitral se obtendrá el laudo y lo interesante es que la Oficina Española de Patentes y Marcas deberá encargarse de la ejecución del mismo, como está bien lo señala el artículo 28 de la Ley de Marcas de 2001 de España ${ }^{21}$.

20. Artículo 9. Otros derechos anteriores.1. Sin la debida autorización, no podrán registrarse como marcas: a) El nombre civil o la imagen que identifique a una persona distinta del solicitante de la marca. b) El nombre, apellido, seudónimo o cualquier otro signo que para la generalidad del público identifique a una persona distinta del solicitante. c) Los signos que reproduzcan, imiten o transformen creaciones protegidas por un derecho de autor o por otro derecho de propiedad industrial distinto de los contemplados en los artículos 6 y 7. d) El nombre comercial, denominación o razón social de una persona jurídica que antes de la fecha de presentación o prioridad de la marca solicitada identifique en el tráfico económico a una persona distinta del solicitante, si, por ser idéntica o semejante a estos signos y por ser idéntico o similar su ámbito de aplicación, existe un riesgo de confusión en el público. A estos efectos, el titular de esos signos habrá de probar el uso o conocimiento notorio de dichos signos en el conjunto del territorio nacional. Cumpliéndose estas condiciones, de igual protección gozarán los extranjeros que de acuerdo con el artículo 3 de esta Ley puedan invocar el artículo 8 del Convenio de París o el principio de reciprocidad, siempre que acrediten el uso o conocimiento notorio en España de su nombre comercial no registrado. 2. No podrán registrarse como marcas el nombre, apellidos, seudónimo o cualquier otro signo que identifique al solicitante del registro si los mismos incurren en alguna de las prohibiciones de registro contenidas en el presente título.

21. Artículo 28. Arbitraje.1. Los interesados podrán someter a arbitraje las cuestiones litigiosas surgidas con ocasión del procedimiento para el registro de una marca, de conformidad con lo establecido en el presente artículo. 2. El arbitraje sólo podrá versar sobre las prohibiciones relativas previstas en los artículos 6.1.b), 7.1.b), 8 y 9 de la presente Ley. En ningún caso podrá someterse a arbitraje cuestiones referidas a la concurrencia o no de defectos formales o prohibiciones absolutas de registro. 3. El convenio arbitral sólo será válido si está suscrito, además de por el solicitante de la marca: a) Por los titulares de los derechos anteriores que hubieren causado la denegación de la marca y, en su caso, por sus licenciatarios exclusivos inscritos. b) Por los titulares de los derechos anteriores que hubieran formulado oposición al registro de la marca y, en su caso, por sus licenciatarios exclusivos inscritos. c) Por quienes hubieran interpuesto recurso o hubieran comparecido durante el mismo. 4. El convenio arbitral deberá ser notificado a la Oficina Española de Patentes y Marcas por los interesados una 
Lo que llama tanto la atención en lo contemplado en la legislación española, es la forma en la que la Oficina Española de Patentes y Marcas deberá realizar todas las actuaciones necesarias para la ejecución del laudo, entre aquellas, por ejemplo, acatar el laudo arbitral y denegar la solicitud de marca. Es decir, obedecer a una entidad privada.

A fin de tener claro ¿de dónde nace aquello que se conoce como arbitrabilidad? y posteriormente aterrizar en la arbitrabilidad de las patentes de invención, es necesario explicar brevemente la arbitrabilidad objetiva y subjetiva que ha sido la más aceptada a nivel doctrinario, es decir, versa sobre la materia que se arbitrará y versa sobre las partes.

\subsection{La arbitrabilidad objetiva o ratione materiae}

Como se mencionó la arbitrabilidad versa sobre la materia por lo que se la considera como una norma protectora de algún interés general o público por lo que filtra materias que podrían considerarse como irrenunciables ${ }^{22}$ y podrá diferir significativamente de quien realice su análisis. En general, si se examina la arbitrabilidad desde la perspectiva de los jueces ordinarios, se lo hará desde la perspectiva de lo que ellos perciben como orden público; no obstante, un tribunal arbitral aplicará los

vez finalizado el procedimiento administrativo de registro de la marca y antes de que gane firmeza el acto administrativo que hubiera puesto término al mismo. Resuelto el recurso de alzada contra el acto que conceda o deniegue el registro, quedará expedita la vía contencioso-administrativa salvo que se haga valer ante la oficina la firma de un convenio arbitral. (Apartado modificado por el apartado 1 de la disposición adicional sexta de la Ley 20/2003, de 7 de julio, de Protección Jurídica del Diseño Industrial) 5. Suscrito el convenio arbitral, y mientras subsista, no cabrá interponer recurso administrativo alguno de carácter ordinario, declarándose la inadmisibilidad del mismo. Igualmente, de haberse interpuesto con anterioridad a la suscripción del convenio, se tendrá por desistido. 6. El laudo arbitral firme producirá efectos de cosa juzgada, de acuerdo con lo establecido en el artículo 37 de la Ley 36/1988, de 5 de diciembre, de Arbitraje, de aplicación en todo lo no previsto por el presente artículo, y la Oficina Española de Patentes y Marcas procederá a realizar las actuaciones necesarias para su ejecución. 7. Deberá comunicarse a la Oficina Española de Patentes y Marcas la presentación de los recursos que se interpongan frente al laudo arbitral. Una vez firme este, se comunicará fehacientemente a la Oficina Española de Patentes y Marcas para su ejecución.

22. Véase, F. GonzÁlez De Cosío, N. 14, p. 196. 
requisitos del orden público internacional, sujeto, por ejemplo, a consideraciones sobre la ejecutabilidad del laudo ${ }^{23}$.

El artículo V de la Convención de Nueva York, apartado 2 a) y b) pone en manifiesto dos escenarios sobre la arbitrabilidad objetiva en el arbitraje internacional: la primera, cuando la materia sobre la que versa el conflicto, no pueda ser objeto de solución por vía de arbitraje según la ley del país en que se pida el reconocimiento y ejecución; y, la segunda, que sea contraria al orden público el laudo cuyo reconocimiento y ejecución se busca'4; esto concuerda con el artículo 36 de la Ley Modelo de la CNUDMI.

No obstante lo mencionado y como todo jurista sabe el derecho no es estático sino más bien evoluciona y cambia, esto lo digo porque lo expuesto cambia en cada legislación y en el tiempo también ${ }^{25}$ siendo que podrá ser percibido de forma distinta, no obstante la regla general es la que se acaba de exponer.

\subsection{La arbitrabilidad subjetiva o ratione personae}

Tanto el mismo artículo $\mathrm{V}$, numeral 1, literal a) del Convenio de Nueva York como el artículo 36, numeral 1, literal a) i) de la Ley Modelo del CNUDMI hacen referencia a la arbitrabilidad subjetiva al mencionar que el laudo arbitral no será válido si una de las partes estaba sujeta a incapacidad ${ }^{26}$ y para GANDía SELLENS, se podría definir esta arbitrabilidad "como la aptitud de las partes para someter a arbitraje una pretensión derivada de una disputa en la que

23. Ibídem.

24. Véase, M. A. Gandía Sellens, El Arbitraje frente a los Litigios Internacionales en materia de Propiedad Intelectual: La Arbitrabilidad y la Adopción de Medidas Cautelares, 1era Ed., Thomson Reuters Aranzadi S.A., 2014, p. 46.

25. Véase, F. González De Cosío, N. 14, p. 196.

26. Véase, M. A. Gandía Sellens, N. 24, p. 48. 
están implicadas" ${ }^{27}$, lo cual ha sido manifestado también por un tribunal arbitral de la CCI que indica que "[1]a arbitrabilidad subjetiva significa que las partes del acuerdo de arbitraje tienen el poder o la capacidad de celebrar un arbitraje válido o no, en otras palabras, que no hay reglas obligatorias aplicables que les impidan celebrar un acuerdo de arbitraje válido; tal puede ser el caso en algún sistema legal si el Estado celebra un acuerdo de arbitraje" ${ }^{28}$.

La arbitrabilidad subjetiva "alude a la posibilidad de que ciertas personas se comprometan a ventilar sus controversias mediante arbitraje" ${ }^{29}$.

Debemos tener en consideración que la forma de llegar a un arbitraje dependerá de la legislación aplicable, sin embargo, no se debe olvidar que la fuente del arbitraje también es importante. Si las partes llegan a un arbitraje por un contrato entonces se puede hablar de que la arbitrabilidad subjetiva se aplica sobre las partes signatarias y queda aún el dilema de la parte no signataria. Por otro lado, por ejemplo, en caso de un arbitraje por un TBI, podría llegar una parte como tercero interesado, que son escenarios que siempre estarán latentes en una controversia.

\subsection{La arbitrabilidad de las patentes de invención respecto de las partes}

En líneas anteriores mencioné brevemente el tipo de negocios jurídicos que podrían existir alrededor de una patente de invención, eso, obviamente, en función de que el titular de la patente fue concedido con ese derecho. Si no hubiera patente

27. Ibídem.

28. Caso CCI No. 14430, párrafo 200. 2: "Subjective arbitrability means that the parties to the arbitration agreement have the power or the capacity to enter into a valid arbitration or, in other words, that there are no applicable mandatory rules preventing them from entering into a valid arbitration agreement; such may be the case in some legal system if the State enters into an arbitration agreement".

29. F. González De Cosío, N. 14, p. 208. 
de invención igualmente podrían existir negocios alrededor de ese "limbo" de creación siempre y cuando, desde mi perspectiva, exista un contrato de por medio; sin un contrato, el creador sin patente no podría hacer uso de ius prohibendi, con un contrato tal vez sí.

La utilidad de este estudio radica en que está más que aceptado a nivel mundial que un arbitraje puede realizarse por la disposición de los derechos puesto que son los derechos que se someten al arbitraje, de forma evidente, son "a los cuales un particular puede libremente renunciar" ya que se utiliza el principio de interpretación jurídica que dice "a majori ad minus, a minori ed majus", es decir, el que puede lo más, puede lo menos ${ }^{30}$.

El profesor Cabanellas, confrontando a Gómez SEgade, menciona que la patente constituye un bien inmaterial y que, al ser un bien, es susceptible de ser objeto de actos jurídicos y esto influye en el tipo de actos que se puedan realizar en su entorno ${ }^{31}$.

Como es conocido la patente sobre una invención es otorgada por la entidad gubernamental competente y por lo tanto es un acto soberano del Estado, razón por la cual existen cuestionamientos respecto del pronunciamiento de un ente privado, como lo es un tribunal arbitral, sobre este tema, lo cual lo expondré más adelante.

A pesar de ello quienes apoyan la arbitrabilidad de las patentes de invención, inclusive para el cuestionamiento de su validez o de infracciones

sugieren que la mayoría de jurisdicciones a nivel mundial permiten al titular de una patente la renuncia, cesión, licenciamiento o transferencia de su derecho de patente a otros, por lo tanto, el titular de la patente también podría

30. Ídem, p. 205.

31. Véase, J. A. Gómez Segade, La patente como objeto del tráfico jurídico, en C. Fernández-NóvoA \& J. A. Gómez Segade, La modernización del Derecho español de patentes, p. 236; y, G. Cabanellas De La Cuevas, N. 1, p. 675. 
agotar sus derechos de patente en un laudo arbitral escogiendo al arbitraje como solución oficial y final para su disputa de patente, y donde el árbitro y las partes han aceptado el resultado ¿quién podría rechazar ese arbitraje como válido? ${ }^{32}$

Si bien esta posición puede ser un poco controversial, no es menos cierto que la manera de declarar una patente de invención como inválida o nula varía de jurisdicción en jurisdicción, e.g. en Estados Unidos las cortes determinan la validez de una patente cuando esta ha sido cuestionada en la contestación del supuesto infractor ${ }^{33}$, lo mismo que sucede en Francia, no obstante en Japón la única autoridad que puede declarar inválida una patente de invención es la Oficina de Patentes ${ }^{34}$.

Más allá de lo mencionado, existe ya un precedente de un tribunal arbitral de la ICC, el cual emitió un laudo relacionado a la validez de la patente de invención en 1989: el caso No. 6097, Wu resume los puntos más destacados del laudo de la siguiente forma:

(i) En un laudo provisional, el tribunal de la ICC sostuvo que la disputa sobre la validez de una patente de invención no podía estar separada de otros problemas en la misma disputa en el arbitraje.

(ii) El tribunal razonó queel titular deuna patente tiene capacidad suficiente para ceder, renunciar o restringir sus derechos.

(iii) En una disputa de infracción o de invalidez, el titular de la patente puede renunciar a sus derechos parcial o completamente en contra de la otra parte.

(iv) Asimismo, el titular de la patente puede notificar de su renuncia a la Oficina de Patente.

(v) El titular de la patente puede vender, donar, transferir todo o parte de sus derechos.

32. Traducción libre. W. H. Wu, "International Arbitration of Patent Disputes", John Marshall Review of Intellectual Property Law, 2011, p. 66.

33. Véase, ídem, p. 61.

34. Ídem, p. 62. 
(vi) El titular de la patente también puede proporcionar la patente en su totalidad o en parte como garantía o prenda. (vii) El titular de la patente puede disponer de sus derechos de la misma manera que otra propiedad, lo cual significa que la parte en el arbitraje puede ceder sus derechos al tribunal arbitral.

(viii)En principio, por lo tanto, no hay obstáculo legal que impida a un tribunal arbitral, facultado por las partes, en pronunciarse, como cuestión preliminar, sobre la validez material de una patente.

(ix) Dicho laudo es vinculante para las partes ${ }^{35}$.

Por así decirlo, no es que el tribunal arbitral se va en contra de la decisión de la entidad gubernamental sino que dispone de los derechos de la patente y como consecuencia de eso, al emitir un laudo, el titular de la patente acata dicho laudo y renunciaría a su derecho de patente; como un laudo arbitral es obligatorio entonces el titular se ve obligado a obedecer.

De forma sorprendentemente complementaria, al otro lado del mundo existió un proceso arbitral en Canadá sobre derechos de autor por la caricatura denominada Caillou ${ }^{36}$, donde la parte actora obtuvo un resultado a su favor pero la parte perdedora atacó el laudo, por ende conoció el caso la Corte de Apelación de Québec y anuló el laudo bajo el argumento que las controversias relacionadas a derechos de autor no pueden ser arbitrales puesto que, entre otras cosas, son contrarias al orden público ya que los derechos de autor pueden ser hecho valor erga omnes siendo que podría afectar a derechos de terceros. No obstante, la Corte Suprema de Canadá manifestó lo contrario y mencionó que el laudo tiene fuerza de cosa juzgada entre las partes pero no obligatorio frente a terceros que no fueron parte del procedimiento ${ }^{37}$,

35. Traducción libre. Ídem, p. 67.

36. Corte Suprema de Canadá, Desputeaux v. Éditions Chouette Inc., 21/03/2003.

37. Ídem, párrafo 62 . 
además sostuvo que la interpretación de la cosa juzgada por parte de la Corte de Apelación fue errónea; cabe exponer, finalmente, que la Corte Suprema manifestó que "el que un derecho sea intransmisible no implica que es irrenunciable y por ende no arbitrable". Esto lleva a la conclusión que no basta que un derecho sea intransmisible o irrenunciable para que no pueda ser sometido a arbitraje, sino que debe existir una prohibición adicional ${ }^{38}$.

\subsection{La arbitrabilidad de las patentes de invención respecto de la sociedad y orden público}

La justificación de esta perspectiva de la arbitrabilidad implica que la sociedad o los terceros que no son partes del arbitraje tengan una "razón" suficiente para aceptar este método alternativo de resolución de conflictos. El término "arbitrabilidad" se refiere a que si ciertas disputas son capaces de someterse a arbitraje, tanto así que varias jurisdicciones establecen que los temas relacionados con el matrimonio, derechos laborales y propiedad intelectual no son arbitrables por las políticas públicas a su alrededor ${ }^{39}$.

El Estado tiene la soberanía para manejar o monitorear las políticas públicas. Por lo tanto, en principio, sería neutral en las decisiones que tome e inclusive tiene los recurso para mantener el balance de los intereses en competencia ${ }^{40}$. Claramente, como una patente de invención es un acto soberano realizado por el Estado; entonces el debate surge cuando un laudo arbitral, realizado por una entidad privada, pueda ir en contra de la política pública cuando la disputa se refiere a la validez de la patente $^{41}$.

38. Véase, F. GonzÁlez De Cosio, N. 14, pp. 205-206.

39. Traducción libre. W. H. Wu, N. 32, p. 61. Véase además, N. Blackaby et al., Redfern and Hunter on International Arbitration, 5ta Ed., 2009.

40. Véase, W. H. Wu, N. 32, p. 62.

41. Traducción libre. Ídem, pp. 61-65. Véase, Corte de Apelaciones de Estados Unidos, 11vo Circuito, Paladino c. Avnet Computer Techs Inc., No. 96-2341, 04/02/1998. 
En ningún momento refuto que el orden público deba ser pasado por alto en un arbitraje relacionado a la validez de una patente de invención porque esto sería no aceptar lo establecido en la Convención de Nueva York y la Ley Modelo de la CNUDMI, cuando se mencionan que se puede denegar el reconocimiento de un laudo arbitral por ser contrario al orden público y por lo tanto su ejecución.

El orden público no es susceptible de una definición única, como lo indicó AsKen en 1987, especialmente en el arbitraje internacional ${ }^{42}$, lo cual fue ratificado en la sentencia discutida en líneas anteriores, por lo que se concluye que el orden público tiene una esencia inconcreta, indeterminable, variable y no perdurable, que, por ende, no da una seguridad de facto ${ }^{43}$.

Ahora bien, por otro lado, el argumento principal sobre la arbitrabilidad y el orden público es que si hacemos un silogismo que inicie desde hecho que una de las características del sistema de patentes sobre una invención es brindar la exclusividad al titular de la patente a cambio del avance y desarrollo de tecnologías aún no conocidas por la sociedad, entonces podemos concluir que la sociedad brinda esa exclusividad, por un tiempo, a cambio de dicha tecnología. Adicionalmente, por ser el caso de que a la sociedad le interesa que esa tecnología sea lo antes posible de dominio público para su explotación entonces le debería interesar que se solucione de forma expedita su disposición. Tanto es así que el interés de la sociedad o interés público se ve reflejado en las partes intervinientes del arbitraje $\mathrm{e}^{44}$.

Ya en la práctica se observa que "los Estados Unidos de América es uno de los países que reconocen el arbitraje para disputas relacionadas con la validez de patentes. [...] Canadá

42. G. Asken, International Commercial Arbitration and International Public Policy, American Society of International Law, 1987, citado por G. QuirogA, N. 15, p. 55.

43. Véase, M. A. Gandía Sellens, N. 24, p. 75.

44. W. H. Wu, N. 32, p. 63. 
y Suiza permiten llegar a acuerdos en problemas de validez de patentes. Francia e Italia se rehúsan a permitir el arbitraje relacionado con la validez de una patente en función de las políticas públicas. En otros países, la validez de una patente no es arbitrable a pesar de que el laudo arbitral sea ejecutable solo como acuerdo de las partes" ${ }^{45}$.

GRANTHAM manifiesta acertadamente que la arbitrabilidad de la Propiedad Intelectual responde netamente a políticas propias de cada país ${ }^{46}$, quien a su vez cita a Alan REDFERn y Martin HunTER quienes manifiestan que

[e]l concepto de arbitrabilidad, llamado así apropiadamente, se relaciona a las limitaciones de la política pública del arbitraje como un método de resolver disputas. Cada Estado puede decidir, de acuerdo con su propia economía y política social, qué asuntos pueden ser resuelto por arbitraje y cuáles no. En casos internacionales, la arbitrabilidad implica el balancear las consideraciones de las políticas de competencia. Los legisladores y las cortes en cada país deben balancear la importancia de reservar asuntos de interés público [como los derechos humanos o asuntos penales] a las cortes en contra del interés público en alentar del arbitraje en asuntos comerciales $^{47}$.

\section{Comentario Final}

Alolargo de este artículo se buscó estudiar la arbitrabilidad de las patentes de invención cuya respuesta arroja la necesidad de analizarla desde varias perspectivas.

La arbitrabilidad subjetiva y objetiva son de las más importantes para la ejecución del laudo arbitral ya que de nada serviría a la parte ganadora obtener un laudo a favor si posteriormente no se lo podría ejecutar.

45. Traducción libre. Ibídem.

46. W. Grantham, "The Arbitrability of International Intellectual Property Disputes", Berkeley Journal of International Law, 1996, p. 179.

47. Traducción propia. N. BlackaBy et al., N. 39. 
Asimismo, los derechos sobre una patente y sus efectos fueron analizados en este artículo desde la perspectiva del titular de la patente y, asimismo, por su efecto ante la sociedad como consecuencia de un arbitraje. Si bien se concluye que el Estado a través de su soberanía puede conceder el derecho de patente sobre un invento, no quita que el titular de la patente pueda disponer de ese o esos derechos de forma amplia hasta el punto de someterlo a un arbitraje, renunciando al mismo por la competencia del tribunal arbitral.

Mediante jurisprudencia internacional se ve como han existido tribunales arbitrales que han entendido este concepto y lo han aplicado, lo cual también es compartido -de cierta forma- por España cuando permite que se resuelvan varios tipos de conflictos relacionados a marcas mediante un arbitraje.

La decisión final sobre la materia que es susceptible de ser resuelta en un arbitraje será, al final, decisión de cada Estado puesto que responderá a decisiones económica o de competencia que decida tomar como respuesta a su realidad social. 